\title{
Spleen Uptake on a Bone Scan
}

\author{
Harleen Kaur, Mitchel Muhleman, and Helena R. Balon \\ Department of Diagnostic Radiology and Molecular Imaging, Oakland University and Beaumont Hospital, Royal Oak, Michigan
}

We present a patient with spleen uptake on bone scanning that was due to sickle cell disease. We also discuss other etiologies for this finding.

J Nucl Med Technol 2017; 45:245-246

DOI: 10.2967/jnmt.117.192427

I $t$ is not uncommon to see incidental uptake of boneseeking agents in the extraosseous structures, for example, the spleen, liver, breast, and lungs. A review of the patient's history, laboratory findings, and other imaging workup provides useful clues in reaching the diagnosis.

\section{CASE REPORT}

A 24-y-old woman with a past medical history of sickle cell disease presented to the hospital complaining of right hip pain after a fall at home. Diagnostic imaging including head CT, hip x-rays, and thoracic and lumbar spine x-rays were unremarkable. As she continued to complain of right hip pain, a bone scan was ordered.

After the intravenous administration of $877 \mathrm{MBq}$ of ${ }^{99 \mathrm{~m}} \mathrm{Tc}-\mathrm{methylene}$ diphosphonate ( $\left.{ }^{99 \mathrm{~m}} \mathrm{Tc}-\mathrm{MDP}\right)$, flow and blood-pool images of the pelvis were obtained (not shown), followed by delayed whole-body and spot views of the pelvis. Whole-body images demonstrated diffuse increased radiotracer uptake in the left upper quadrant of the abdomen just superolateral to the left kidney, suggesting uptake in the spleen (Fig. 1). Diffuse increased uptake throughout the skull, distal femurs, and proximal tibias was in a pattern characteristic of bone marrow hyperplasia.

The peripheral blood smear showed normocytic-normochromic anemia with sickle cells, Howell-Jolly bodies, and Pappenheimer bodies. The patient also had a history of iron overload from multiple transfusions and was on chelation therapy.

Pappenheimer bodies (Fig. 2) are blue-purple inclusion bodies located within the red blood cells formed by phagosomes that have engulfed excessive amounts of iron. They

Received Feb. 27, 2017; revision accepted May 16, 2017.

For correspondence or reprints contact: Harleen Kaur, Beaumont Health, 3601 W. 13 Mile Rd., Royal Oak, MI 48073.

E-mail: Harleen.kaur@beaumont.org

Published online Jun. 13, 2017.

COPYRIGHT (C) 2017 by the Society of Nuclear Medicine and Molecular Imaging. are present in diseases such as sideroblastic anemia, hemolytic anemia, and sickle cell disease.

Howell-Jolly bodies (Fig. 2) are basophilic nuclear remnants (clusters of DNA) in circulating erythrocytes. These inclusions are normally removed by the spleen but persist in individuals with functional hyposplenia or asplenia. Common causes include asplenia (postsplenectomy), trauma to the spleen, and autosplenectomy caused by sickle cell anemia.

\section{DISCUSSION}

The most common causes of uptake in the spleen on the bone scan are hemosiderosis, hemochromatosis, and sickle cell disease. Some of the uncommon causes of splenic uptake are neoplastic deposits to the spleen (e.g., from breast cancer, Hodgkin disease), splenic hemangioma, splenic artery calcification, frequent platelet and red blood cell transfusions (1), and thalassemia major. Rare causes of splenic uptake include glucose-6-phosphate dehydrogenase deficiency.

Hepatic and splenic uptake of ${ }^{99 \mathrm{~m}} \mathrm{Tc}-\mathrm{MDP}$ has also been reported when ${ }^{99 \mathrm{~m}} \mathrm{Tc}-\mathrm{MDP}$ is injected within a short interval or up to $2 \mathrm{~d}$ after the administration of gadolinium-diethylenetriamine pentaacetic acid (Gd-DTPA) MRI contrast agents and even when ${ }^{99 \mathrm{~m}} \mathrm{Tc}-\mathrm{MDP}$ is injected before Gd-DTPA $(2,3)$. Another cause of splenic uptake could be a recent prior radionuclide study, such as with ${ }^{99 \mathrm{~m}} \mathrm{Tc}$-sulfur colloid or ${ }^{111}$ In-labeled white blood cells. Both will additionally demonstrate radiotracer uptake in the liver.

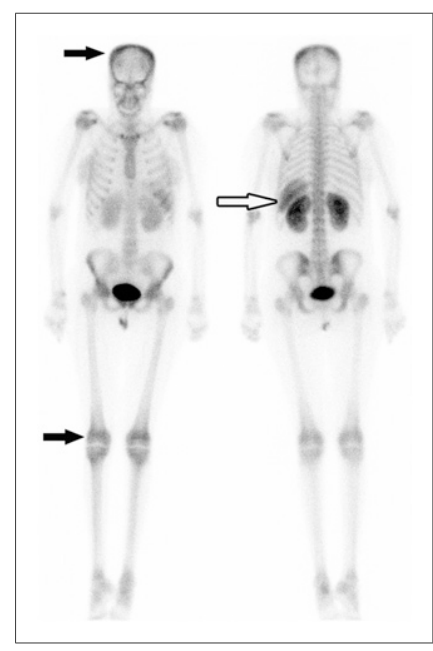

FIGURE 1. Anterior (left) and posterior (right) bone scans show unexpected uptake in left upper quadrant characteristic of spleen (black and white arrow). There is also increased radiotracer uptake in skull, distal femurs, and proximal tibias (black arrows) characteristic of pattern of bone marrow expansion. 


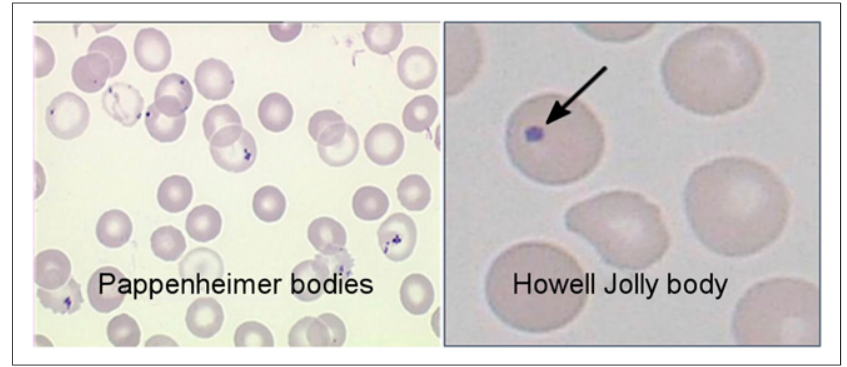

FIGURE 2. Pappenheimer (left) and Howell-Jolly (right) bodies.

The mechanism of splenic uptake of bone-seeking agents in sickle cell anemia has been presumed to be deposition of calcium. Microscopic deposits of calcium that could not be detected radiographically might also cause uptake of ${ }^{99 m}$ Tc-MDP. Several ultrastructural studies have demonstrated mitochondrial binding of calcium ions in necrotic muscle cells, within a crystalline structure similar to that of hydroxyapatite (4).

Hemosiderosis occurs as a result of recurrent transfusion and increased deposition of iron from the sequestration of abnormal red blood cells within the spleen. Several studies including a study by Jones et al. (5) proposed that iron deposits might be responsible for uptake of bone-seeking radionuclides.

The shortened survival of the abnormal sickle cells leads to a compensatory marrow expansion throughout the skeleton. An expanded marrow space results in increased uptake of tracer in the calvarium, periarticular locations in the long bones, and even the distal extremities.

\section{CONCLUSION}

It is not uncommon to see incidental uptake of boneseeking agents in the extraosseous structures, for example, the spleen, liver, breast, and lungs. A review of the patient's history, laboratory findings, and other imaging workup provides useful clues in reaching the diagnosis.

Spleen uptake on a bone scan can be caused by number of diseases including sickle cell disease as discussed in our case report. It is presumed to be caused by microscopic or macroscopic splenic calcifications or prior infarcts. Iron overload in patients receiving blood transfusions can be another cause.

\section{REFERENCES}

1. De Marini P, Laplace A, Matuszak J, Fornecker LM, Namer IJ. Spleen uptake on bone scan after frequent platelet and RBC transfusions. Clin Nucl Med. 2016;41:802803 .

2. Zhang W, Chen B, Deng H, Yang T, Ou X. Hepatic and splenic uptake on bone scintigraphy in patients with intravenous administration of ${ }^{99 \mathrm{~m} T c}$ methylene diphosphonate prior to gadolinium-containing contrast. Clin Nucl Med. 2013;38:219-220.

3. Pak K, Kim SJ, Kim IJ, Suh KT. Hepatic uptake of Tc-99m DPD on bone scintigraphy: the influence of the interval with gadolinium-containing contrast of MRI. Clin Nucl Med. 2012;37:134-136.

4. Yapar AF, Aydin M, Reyhan M. Diffuse splenic Tc-99m MDP uptake in hypersplenic patient. Ann Nucl Med. 2004;18:703-705.

5. Jones AG, Francis MD, David MA. Bone scanning radionuclide reaction mechanisms. Semin Nucl Med. 1976;6:3-18. 